\title{
BMJ open Helmet use in BIXI cyclists in Toronto,
Canada: an observational study
}

Marissa Bonyun, ${ }^{1}$ Andi Camden, ${ }^{2}$ Colin Macarthur, ${ }^{1,3}$ Andrew Howard ${ }^{1,4,5,6}$

To cite: Bonyun M, Camden A, Macarthur C, et al. Helmet use in BIXI cyclists in Toronto, Canada: an observational study. BMJ Open 2012;2:e001049. doi:10.1136/

bmjopen-2012-001049

- Prepublication history for this paper is available online. To view these files please visit the journal online (http:// dx.doi.org/10.1136/ bmjopen-2012-001049).

Received 21 February 2012 Accepted 10 May 2012

This final article is available for use under the terms of the Creative Commons Attribution Non-Commercial 2.0 Licence; see http://bmjopen.bmj.com

${ }^{1}$ Faculty of Medicine, University of Toronto, Toronto, Canada ${ }^{2}$ Child Health Evaluative Sciences, The Hospital for Sick Children, Toronto, Canada

${ }^{3}$ Department of Paediatrics, University of Toronto, Toronto, Canada

${ }^{4}$ Orthopaedic Surgery, The Hospital for Sick Children, Toronto, Canada ${ }^{5}$ Department of Surgery, University of Toronto,

Toronto, Canada

${ }^{6}$ Health Policy, Management and Evaluation, University of Toronto, Toronto, Canada

Correspondence to Dr Andrew Howard; andrew.howard@sickkids.ca

\section{ABSTRACT}

Objective: To investigate the use of helmets for cyclists choosing to use BIXI bikes in comparison to personal bike riders in the City of Toronto.

Design: Cross-sectional study design.

Setting: Cyclists were observed in Toronto, Canada.

Participants: Of the 6732 sample size, 306 cyclists on $\mathrm{BIXI}$ bikes and 6426 personal bike riders were observed.

Outcome measure: The outcome of interest was helmet use.

Results: Overall, $50.3 \%$ of cyclists wore helmets. The proportion of BIXI bike riders using helmets was significantly lower than the proportion of helmet users on personal bikes ( $20.9 \%$ vs $51.7 \%$, respectively, $\mathrm{p}<0.0001$ ).

Conclusions: Although the BIXI bike programme has provided an alternate means for Torontonians to use a bicycle, cyclists using BIXI bikes are much less likely to wear a helmet. Since the prevalence of helmet use in cyclists in general is already low, helmet use should be especially promoted in BIXI bike riders in order to promote a safe and healthy environment for cyclists.

\section{INTRODUCTION}

Urban cycling promotes healthy living and also minimises environmental pollutants from vehicle emissions. Bike-sharing initiatives, therefore, provide communities with a means to an active healthy lifestyle via a sustainable means of transportation. ${ }^{1}$

Multiple variations of bike-sharing programmes have evolved across the world in the last 46 years, yet the core design among all programmes remains the same-a finite number of bikes are placed throughout a community for citizens and visitors to 'borrow' at their leisure for shorter commutes within designated community zones. $^{1}$ The target population for these programmes is within-city commuters who can benefit from the use of a temporary bicycle and avoid the worry of parking and locking a bike while at their destination.

The most prominent bike-sharing programme in North America is BIXI (named according to a combination of the

\section{ARTICLE SUMMARY}

\section{Article focus}

- We investigated the use of helmets for cyclists choosing to use BIXI bikes in comparison to personal bike riders in the City of Toronto.

- We hypothesised that the proportion of helmet users using BIXI bikes would be significantly lower than those on personal bikes.

\section{Key messages}

- Cyclists using BIXI bikes in Toronto are less likely to wear a helmet than cyclists riding their own bike; only $20.9 \%$ of all BIXI cyclists wear helmets compared with $51.7 \%$ of cyclists riding a personal bike.

- More men than women ride bicycles in Toronto.

- Women in Toronto were more likely to wear a helmet while cycling.

Strengths and limitations of this study

- This is the first study (to our knowledge) investigating helmet use in a bike-sharing system. Additional strengths include the prospective study design, number of observations, randomly selected observation sites and stratified analyses by sex.

- The data were collected by one of the observer not blinded to the study hypothesis; observations were limited to presumed commuter hours in the downtown core of Toronto and we were unable to account for variables previously associated with helmet use, including income, education and age.

elements of the programme: 'BIcycle' and 'taXI'). BIXI was also the first bike-sharing company in Canada, initially in Montreal in 2009 and to the Toronto downtown core on 3 May 2011.2 Eighty solar-panelled stations were placed throughout the city (Figure 1). Each station consists of a pay station and bike docks, distributed according to population density, frequent travel paths and frequent bicyclist locations $^{2}$ (Figure 2).

Users of BIXI bikes can subscribe for a 1year or 30-day access pass or they can rent a bike by purchasing a $24 \mathrm{~h}$ or $72 \mathrm{~h}$ access pass. Requirements stated for usage of the BIXI bikes are that cyclists are 18 years of age or older and at least $1.24 \mathrm{~m}$ tall; however, 
Figure $1 \mathrm{BIXI}$ bike docking station locations, Toronto, 2011.

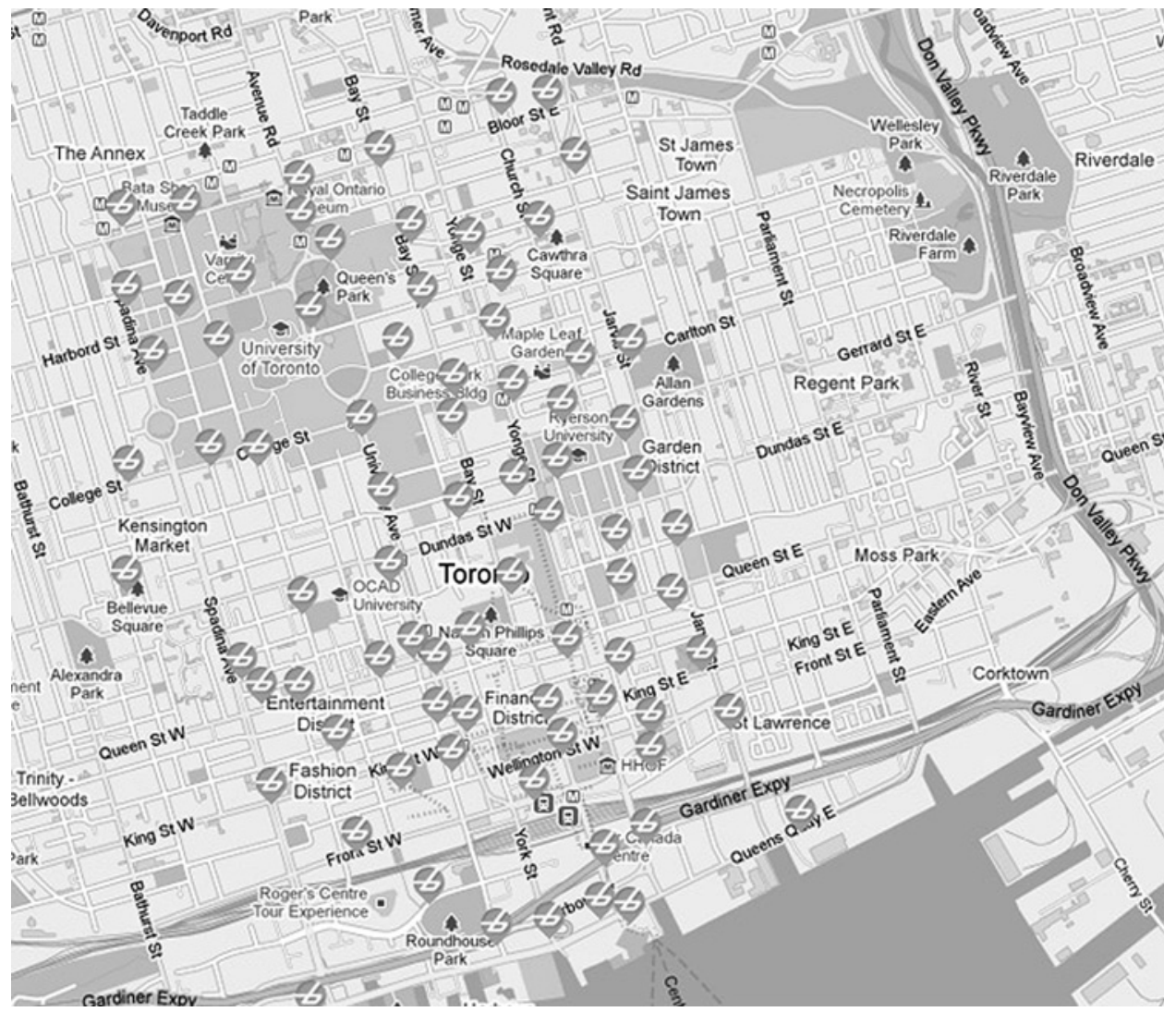

after a credit card has been registered or an account has been created, there is no actual method of monitoring who rides the bicycle. Furthermore, there is no requirement for helmets to be worn while on the bicycle, though BIXI encourages riders to wear a helmet while cycling. $^{2}$

Cyclists over 18 years of age in Toronto make the choice of whether or not to wear a bicycle helmet because helmet legislation in Ontario only applies to children. It was initially estimated that bicycle helmets decrease the risk of head injury by $85 \% .^{3}$ More recent estimates question

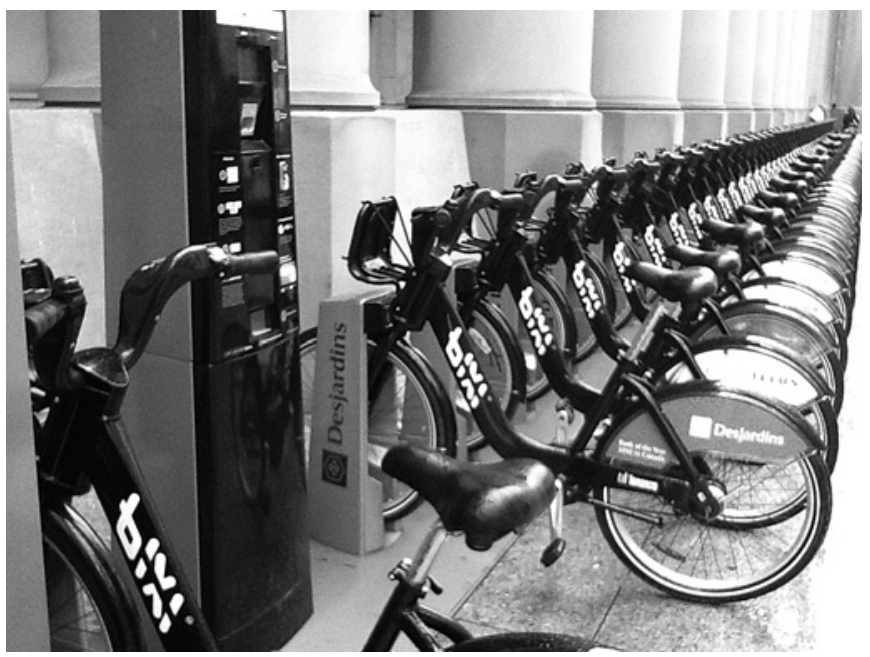

Figure 2 BIXI bike kiosk, with pay station and bike dock, Toronto, 2011. whether the protective effect is that high, but meta-analyses consistently demonstrate that bicycle helmets prevent head injuries. ${ }^{4}$ The 2001-2007 Canadian Community Health Surveys showed that $41 \%$ of youth and adults in Ontario regularly use helmets while cycling. ${ }^{5}$ Recent observational data revealed that only $50 \%$ of cyclists use helmets in the Greater Toronto Area. ${ }^{6}$

In the City of Toronto, 13475 collisions were reported between cyclists and motor vehicles between 1986 and 1996, resulting in 38 cyclist fatalities. ${ }^{7}$ In the USA, as high as 500000 emergency care visits are attributable to injuries sustained while riding a bicycle, resulting in 900 deaths annually. Head injuries and facial traumas represent one-third of these emergencies, with threequarters of all bicycle-related deaths being attributable to head injuries. ${ }^{8}$

With the advent of the BIXI bike-sharing system throughout downtown Toronto and the promotion of bicycle use for commuters, we were interested in examining the prevalence of helmet use by BIXI bike users. To our knowledge, no study has examined the prevalence of helmet use in bike-sharing programmes. The current study compared the use of helmets by cyclists choosing to use BIXI bikes with personal bike riders in the City of Toronto. We hypothesized that the proportion of helmet users using BIXI bikes would be significantly lower than those on personal bikes because there is no way to obtain a helmet at the same time as a BIXI is hired. There are little data about helmet use in bike-sharing systems but the information available suggests lower helmet use if the helmet is not supplied with the bike. ${ }^{9}$ 


\section{METHODS}

We used a cross-sectional design to determine the proportion of helmet users in downtown Toronto, Canada, for cyclists on personal bikes versus those on BIXI bikes. During an observational period of $1 \mathrm{~h}$, a researcher observed how many cyclists on personal bikes and how many cyclists on BIXI bikes wore or did not wear helmets. Observations were made between July and September 2011 and took place during weekday 'commuter hours' (ie, between 07:00 and 10:00 or between 15:00 and 18:00). As the BIXI bike main use is to facilitate transportation along short distances, ${ }^{2}$ and most of the cyclist commuter traffic occurs during these 'rush hour' time periods, this time period was chosen to maximise the number of both BIXI bike and personal bike cyclists observed.

The main exposure variable was type of bicycle. For the purposes of this study, a 'bicycle' or 'bike' was defined by the researchers to constitute a two-wheeled, non-fuel-consuming foot pedal-based method of transportation, where the rider is seated and can hold handlebars in front of them. The 'BIXI bike' was identified by its characteristic BIXI shape and/or colours, ${ }^{2}$ whether being removed or returned from the docking station or being ridden past the point of observation. A 'personal bicycle' was defined as any bicycle of a brand other than BIXI. The outcome of interest was helmet use. A 'helmet' was defined for the purposes of this project to constitute a solid protection device worn on the head, with a chinstrap, as a means of promoting personal safety to protect the head from impact in the event of a fall or collision. Observed sex of the bicycle riders was also recorded as a covariate to understand differences in helmet use by sex.

Using the map of the BIXI bike docking, operational docking stations were assigned numbers from 1 to 79 sequentially from north-east to south-west. Twenty-five operational stations were randomly selected to designate observation points for the study. During each observation period, a researcher sat in a location with the BIXI bicycle docking station in clear view and noted all cyclists within view (approximately $20 \mathrm{~m}$ radius from the BIXI bicycle docking station), no matter which direction they were travelling. Cyclists of all ages were included in the study. No contact was made with the cyclists. Ethical approval was obtained from the research ethics review board at the Hospital for Sick Children in Toronto, Ontario.
A tally was collected for one of four categories: (1) BIXI bike riders with a helmet, (2) BIXI bike riders without a helmet, (3) personal bike riders with a helmet or (4) personal bike riders without a helmet. Each category was subdivided by observed sex (male, female or unsure).

The required sample size for each of the two groups (BIXI bike cyclists and personal bike cyclists) was based on calculations using the formula for sample size calculations for two independent sample tests for proportions with an estimated effect size of $10 \%$ and an estimated proportion of $50 \%$ of helmet use in personal bike users ${ }^{6}$ for a two-sided test with a $5 \%$ level of significance, $80 \%$ power. The sample size calculation revealed that 407 subjects were needed per group.

Proportions of helmet users in BIXI bike cyclists and personal bike cyclists were calculated and compared between groups by $\chi^{2}$ analysis using Epi Info (V.3.5.3) StatCalc. Each group was stratified by sex (male, female or 'unsure'), and the proportion of helmet users within groups by sex was calculated.

\section{RESULTS}

A total of 6732 cyclists were observed, including 306 BIXI bike cyclists and 6426 personal bike cyclists. When stratified by sex, a total of 4307 male cyclists and 2399 female cyclists were observed. Within groups, there were 234 male BIXI cyclists and 72 female BIXI cyclists, and 4073 male and 2327 female cyclists on personal bikes. For 24 helmet users and two non-helmet wearing cyclists on personal bikes, male or female designation could not be assigned; however, this represented a very small number of cyclists observed $(0.4 \%)$ and thus these observations were not included in the analysis by sex. The remaining 6706 observations were included in the analysis.

Twenty-one per cent of bike riders wore helmets while on BIXI bikes. This was significantly lower than the prevalence of helmet use by personal bike riders $(51.7 \%$; uncorrected $\left.\chi^{2}=110.48, \mathrm{p}<0.0001\right)$. Both male and female personal bike riders were statistically significantly more likely to wear helmets compared with male and female BIXI bike riders (males: $47.9 \%$ vs $20.1 \%$, respectively; uncorrected $\chi^{2}=68.84, \mathrm{p}<0.0001$, females: $57.8 \%$ vs $23.6 \%$, respectively; uncorrected $\chi^{2}=33.26$, $\mathrm{p}<0.0001)$. The results for across-group comparisons of helmet use in BIXI bike users and personal bike users are summarised in table 1.

Table 1 Observed helmet use by bicycle type, Toronto, 2011

\begin{tabular}{|c|c|c|c|c|c|c|}
\hline & \multicolumn{2}{|l|}{ BIXI bike } & \multicolumn{2}{|c|}{ Personal bike } & \multirow[b]{2}{*}{$\chi^{2}$} & \multirow[b]{2}{*}{ p Value } \\
\hline & Riders (n) & Helmet, n (\%) & Riders (n) & Helmet, n (\%) & & \\
\hline Total observed & 306 & 64 (20.9) & 6426 & 3320 (51.7) & 110.48 & $<0.0001$ \\
\hline Females & 72 & 17 (23.6) & 2327 & 1345 (57.8) & 33.26 & $<0.0001$ \\
\hline Males & 234 & $47(20.1)$ & 4073 & 1951 (47.9) & 68.84 & $<0.0001$ \\
\hline Could not determine sex & 0 & $0(-)$ & 26 & $24(92.3)$ & \multicolumn{2}{|c|}{ (Not analysed) } \\
\hline
\end{tabular}

The proportion of riders using helmets was lower on BIXI bicycles and this was statistically significant overall and by sex. 
Compared with male bike riders, female bike riders were more likely to wear helmets. On personal bikes, women wore helmets more often than men $(57.8 \%$ vs $47.9 \%$, respectively; $\left.\chi^{2}=58.10, \mathrm{p}<0.0001\right)$. On BIXI bikes, gender differences in helmet use were not statistically significant $(23.6 \%$ of females vs $20.1 \%$ of males, respectively; $\left.\chi^{2}=0.41, \mathrm{p}<0.5201\right)$.

Overall, whether riding a BIXI bike or a personal bike, 3384 of 6732 cyclists observed $(50.3 \%)$ wore helmets. The observed prevalence of BIXI bike usage in Toronto was $4.5 \%$.

\section{DISCUSSION}

The proportion of BIXI bike users $(64,20.9 \%)$ who were wearing a helmet, regardless of sex, was significantly lower than the proportion of personal bike users (3320, $51.7 \%$ ) wearing a helmet. This means that, although BIXI was introduced with the purpose to promote the use of cycling for short commutes within the city, the BIXI bike programme appears to decrease the alreadylow proportion of helmet users. Since the use of helmets while cycling has been recognised as a means of reducing significant head injuries, severe facial trauma and even death, ${ }^{3} 4810$ the advent of a bike-sharing programme that decreases helmet use may increase the risk of severe injury and/or fatalities in the event of a collision while cycling. This is especially dangerous in an urban centre such as Toronto, where cyclists often are found alongside motor vehicles on busy streets in peak commuting hours.

As has been replicated in previous studies, ${ }^{5} 11$ a large sex difference was observed both with respect to total cyclists and helmet users. Although women were less likely to ride a bicycle overall, women who did use a bicycle were more likely to wear a helmet. This same pattern translated to BIXI bike users as well, with women less likely to use the BIXI bikes.

This study represents the first investigation (to our knowledge) of helmet use in a bike-sharing system. A similar pattern may extend to bike-sharing systems worldwide. As of 2008, there have been fatalities reported while using bike-sharing systems internationally: three fatalities in Paris's Velib programme, three collisions in New Zealand's NextBike, one collision in Hangzhou's bike-sharing system and one in the North American BIXI system. ${ }^{1}$ Given the nature of collision data, these statistics may be under-reported. Since helmet use has been shown to protect against severe injuries and fatalities among collisions while cycling, ${ }^{34810}$ this suggests that bike-sharing systems, such as BIXI, should be accompanied by actions to promote helmet use. However, as bikesharing programmes cater to cyclists on-the-go within urban centres, ${ }^{1}$ it is imperative that solutions to promote helmet use be amenable to the commuter population and available at the point of bike rental.

One difficulty noted internationally is that helmet use may be legislated (or not) by a municipal, state/province or nationally country. In cities where helmet use is mandatory, bike-sharing systems have already begun to address the problem of low helmet use, providing a model through which other bike-sharing systems may approach this dilemma in injury prevention. ${ }^{12}$ As helmets are mandatory for cyclists in Australia, a bikesharing system in Melbourne piloted a project where helmets could be purchased or rented through vending machines at the point of bike rental or at local convenience stores around the city. ${ }^{13}$ Pending helmet uptake data through this pilot, other bike-sharing companies like BIXI could model this project in order to promote helmet use within their consumers. BIXI bike could also work towards providing machines near BIXI stations for helmet dispensing at the point of BIXI bike rental.

There are several limitations associated with the current study. This was the first study of its kind to observe and count BIXI bike riders and personal bike riders. The fact that only one observer who was not blinded to the hypothesis collected the data for the study could have introduced a data collection bias. However, since the observer was measuring an objective outcome through the tallying of bicyclists in the area at each station, it is unlikely that any significant personal or subjective bias was introduced. Furthermore, this study only observed cyclists within the presumed 'commuter' hours within the downtown core such that the main population targeted for the study was cyclists commuting to work or to school. Previous studies have found that statistics of helmet use vary with income and education, ${ }^{11}$ though in this study, all riders, regardless of attire or presumed reason for riding the bicycle, were counted towards the study population. Furthermore, although all observations were made during commuter hours, the locations of the randomly selected BIXI bike stations spanned many areas of downtown Toronto, including financial districts, local parks, intercity areas and school campuses. ${ }^{2}$ This layout in BIXI bike stations allows the programme to cater to a wide array of Torontonians and helped to increase the diversity of our study population to be representative of the natural Toronto population. This study did not classify cyclists by age; as a result, all analyses were conducted regardless of the age of the cyclists. Patterns of helmet use have been reported to vary with age, with youth and adolescents in Ontario most likely to wear a helmet. ${ }^{11}$ BIXI bicycles are only available for those 18 and over, so it is unlikely that the presence of children under the helmet legislation would have significantly impacted the study's results. Finally, individual cyclists were not identified so may have been observed more than once.

With an increasing focus on Toronto to be a healthy, environmentally friendly city, cycling continues to be a promising sustainable means of transportation. Although the BIXI bike programme has provided an alternate means for Torontonians to use a bicycle that is publically available for short-term within-city routes, ${ }^{2}$ its indirect negative effect on helmet use for cyclists poses 
a threat to cyclists' safety. Efforts to promote cycling while protecting cyclists from severe injury should be made a priority in the promotion of a healthy and safe Toronto.

Contributors MB: study design, data collection, data analysis and interpretation, writing and editing of the manuscript, and final approval of the manuscript. AC: study design, data analysis and interpretation, writing and editing of the manuscript, and final approval of the manuscript. CM: consultation on design, data interpretation, writing and editing of the manuscript, and final approval of the manuscript. AH: conceptual framework and study design, data analysis and interpretation, writing and editing of the manuscript, and final approval of the manuscript.

Funding This research received no specific grant from any funding agency in public, commercial or not-for-profit sectors.

Competing interests None.

Ethics approval Ethics approval was provided by the research ethics review board of the Hospital for Sick Children in Toronto, Ontario.

Provenance and peer review Not commissioned; externally peer reviewed.

Data sharing statement No additional data available.

\section{REFERENCES}

1. Shaheen SA. Bikesharing in Europe, the Americas, and Asia. Transp Res Rec 2010;2143:159.

2. BIXI Toronto. BIXI Toronto. https://toronto.bixi.com/ (accessed 5 Nov 2012).
3. Thompson RS, Rivara FP, Thompson DC. A case-control study of the effectiveness of bicycle safety helmets. N Engl J Med 1989;320:1361-7.

4. Elvik R. Publication bias and time-trend bias in meta-analysis of bicycle helmet efficacy: a re-analysis of Attewell, Glase and McFadden, 2001. Accid Anal Prev 2011;43:1245-51.

5. Dennis J, Potter B, Ramsay T, et al. The effects of provincial bicycle helmet legislation on helmet use and bicycle ridership in Canada. Inj Prev 2010;16:219-24.

6. Page JL, Macpherson AK, Middaugh-Bonney T, et al. Prevalence of helmet use by users of bicycles, push scooters, inline skates and skateboards in Toronto and the surrounding area in the absence of comprehensive legislation: an observational study. Inj Prev 2012;18:94-7.

7. Lucas WJ. A Report on Cycling Fatalities in Toronto 19861998-Recommendations for Reducing Cycling Injuries and Death. Province of Ontario: Chief Coroner, 1998.

8. Thompson DC, Rivara FP, Thompson R. Helmets for preventing head and facial injuries in bicyclists. Cochrane Database Syst Rev 2000; (2):CD001855.

9. Constant $A$, Messiah A, Felonneau ML, et al. Investigating helmet promotion for cyclists: results from a randomised study with observation of behaviour, using a semi-automatic video system. PLoS One 2012;7:e31651.

10. Attewell RG, Glase K, McFadden M. Bicycle helmet efficacy: a metaanalysis. Accid Anal Prev 2001;33:345-52.

11. Irvine A, Rowe BH, Sahai V. Bicycle helmet-wearing variation and associated factors in Ontario teenagers and adults. Can J Public Health 2002;93:368-73.

12. Midgley P. Bicycle-Sharing Schemes: Enhancing Sustainable Mobility in Urban Areas. United Nations Commission on Sustainable Development, 2011. CSD19/2011/BP8.

13. VicRoads. Melbourne Bike Share. http://www.melbournebikeshare com.au/ (accessed 5 Nov 2012). 